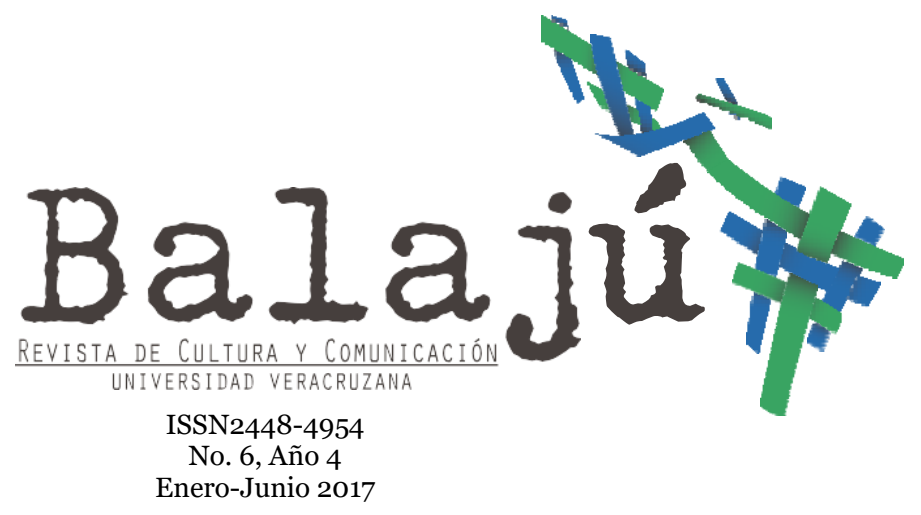

\title{
Fragmentación, familia e identidad en Misión de Chichimecas, San Luis de la Paz, Guanajuato
}

Fragmentation, Family and Identity in Mission of Chichimecas, San Luis de la Paz, Guanajuato

Ana Elizabeth Villegas Ortiz

Universidad de Guanajuato

k-rato@hotmail.com

\section{RESUMEN}

Este texto presenta una primera aproximación al estudio de la organización familiar, el parentesco, las políticas públicas y la identidad, en una comunidad indígena del estado de Guanajuato. El documento se apoya en la revisión de fuentes históricas y en información de primera mano recabada a partir del trabajo de campo realizado en dicha comunidad entre 2010 y 2012. Los datos obtenidos a través de entrevistas, recorridos y observación participante se han complementado con información bibliográfica sobre el área de estudio.

\begin{abstract}
This article presents a first approach to the study of family organization, kinship, public policies and identity in an indigenous community in the state of Guanajuato. The text is based on a review of historical sources as well as firsthand evidence gathered during fieldwork carried out in Mission of Chichimecas during 2010 and 2012. The data obtained through interviews, visits and participant observation are supplemented with bibliographical information about the community.
\end{abstract}

\section{PALABRAS CLAVES}

Familia, identidad, etnografía.

\section{KEYWORDS}

Family, identity, ethnography. 


\section{Fragmentación, familia e identidad en Misión de Chichimecas, \\ San Luis de la Paz, Guanajuato \\ Ana Elizabeth Villegas Ortiz ${ }^{1}$}

\section{Introducción}

La documentación de los procesos por los que atraviesa Misión de Chichimecas es importante debido a que esta localidad constituye uno de los últimos reductos de población indígena que permanecen en el estado de Guanajuato. La migración interna e internacional, así como el desplazamiento gradual de la lengua indígena se observan como indicios de importantes procesos de cambio cultural en la localidad. Tales procesos se encuentran estrechamente relacionados con los cambios de distribución territorial de la organización familiar y con las normas de filiación y otras prácticas culturales añejas propias de esta población indígena.

Considerando estos señalamientos, este documento tiene dos propósitos centrales. El primero es exponer los principales rasgos socioculturales y demográficos observados recientemente en la zona en cuestión. Con base en la información descriptiva, etnográfica y documental, en este documento proponemos iniciar una reflexión en cuanto al modo como estos procesos de cambio cultural afectan la construcción de la identidad y el sentido de unidad en Misión de Chichimecas

Adicionalmente, con base en esta perspectiva antropológica, se busca también proponer una reflexión acerca de los procesos de fragmentación y de división observados en la comunidad, propiciados principalmente por la intervención del Estado, a lo que se añade la construcción de una carretera que dividió a la comunidad en dos: "Misión de arriba" y "Misión de abajo", enfatizando el papel que la organización familiar desempeña ante el cambio cultural de este grupo indígena.

La estructura del documento es la siguiente: se inicia con la descripción del área de estudio y un recuento histórico de la conformación de la misma. A continuación, se exponen los principales aspectos sociodemográficos de Misión de Chichimecas. En los siguientes apartados, se muestra la organización políticoadministrativa de la localidad, las características de la organización familiar y elementos relacionados con el parentesco en Misión de Chichimecas. Finalmente, en las reflexiones finales se busca la relación de los cambios ocurridos en esta comunidad y en la región aledaña con posibles transformaciones en la organización familiar y en la constitución de la comunidad.

\section{Misión de Chichimecas: caracterización y recuento histórico}

Misión de Chichimecas se ubica a dos kilómetros al oriente de San Luis de la Paz, ${ }^{2}$ aunque el crecimiento de la ciudad hacia el noroeste 3 y el respectivo proceso de conurbación de las comunidades aledañas invisibilizan la división física entre el municipio y la comunidad. El crecimiento hacia el noroeste se visualizó a partir de la construcción del libramiento que va de San Luis de la Paz a Victoria en los años setenta y que atraviesa la comunidad fracturándola, como hemos dicho, en dos: Misión de arriba y Misión de abajo. Cabe señalar que esta cicatriz física marcada en

\footnotetext{
${ }^{1}$ Licenciada en Antropología Social por la Universidad de Guanajuato.

${ }^{2}$ Véase el anexo 1.

3 Rumbo al municipio de Victoria.
} 
el territorio vino a destacar aún más la separación que ya se venía dando en torno a aspectos sociales y culturales, como el acceso a servicios públicos, el acceso a la educación, el uso y desuso de la lengua, el contacto con el grupo mestizo y lo que significa ser chichimeca en cada una de las dos partes de la localidad.

En la actualidad, el asentamiento de ascendencia chichimeca es uno de los pocos núcleos de población indígena originaria que perviven en el estado de Guanajuato y que conservan parcialmente su idioma, el chichimeca-jonaz. Se ubica dentro de la jurisdicción de San Luis de la Paz, al noreste del estado, "en lo que comprende parte de la Sierra Gorda y una de las zonas más deprimidas y marginadas a nivel estatal” (SEP, 1987: 120).

Históricamente, al momento de la conquista, en la región de lo que hoy comprende Guanajuato, lo que se encuentra es un territorio habitado rotativamente por grupos de cazadores-recolectores denominados chichimecas. Los chichimecas eran bandas nómadas que habitaban el área de Aridoamérica, hacia el norte de los límites de Mesoamérica. Esta región era una zona semidesértica, en donde "no se había desarrollado la agricultura intensiva, ni se habían desarrollado grandes edificaciones características de las culturas mesoamericanas" (Kirchoff, 2002; 82). El término chichimeca era utilizado por los grupos mesoamericanos para nombrar a estas bandas nómadas y denotar su bajo nivel de desarrollo cultural; la acepción más aceptada entre los estudiosos es la traducción del náhuatl en la cual chichimeca significa "linaje de perros" (Santa María, 2003: 113).4

Durante la Colonia, en 1546, ocurre el descubrimiento de uno de los elementos más importantes para el soporte de la economía colonial: las minas de Zacatecas, por lo que se buscó establecer un camino de México a Zacatecas, lo cual se logró al fundar fuertes o poblados ubicados entre sí a no más de un día de distancia, lo que permitiría llevar el mineral a salvo de los ataques chichimecas (Powell, 1996: 19-68).

Tal fue el caso de San Luis de la Paz, que se funda en 1552, con otomíes provenientes de Xilotepec (Ramírez, 1952: 41) y con un grupo de chichimecas al que se logró reducir y asentar tras una prolongada guerra (la guerra del Mixtón) "bajo la condición de que el virrey les suministrara maíz, carne y ropa” (Alegre, 1956: 80). Para 1594, la fundación del pueblo se hizo oficial y dos jesuitas se hicieron cargo de la iglesia. La parte de la población chichimeca que se asentó en el poblado la comprendían "grupos tales como el copuz, el guajabán, el pame, guachichil, uascan, además de tarascos, mexicanos y matlazincas, tal como lo señalan las actas del primer libro de bautismos que corre de 1590 a 1635" (Rabell, 1986: 25).

Desde la fundación y el inicio del desarrollo de la vida sedentaria de estas comunidades en Misiones, no hay mucha información en cuanto a lo que sucedió con ellos desde el siglo XVII hasta finales del siglo XIX. Lo que se sabe es que trabajaron en las actividades económicas de las haciendas de los jesuitas. Después, "a finales del siglo XIX, en la comunidad se registraron conflictos derivados de la invasión del territorio tras el crecimiento de las haciendas aledañas"; se estableció la Ley Reglamentaria sobre Repartición de Tierras Ejidales y Constitución del Patrimonio Parcelario Ejidal, en 1928. Ante esto, los chichimecas, de acuerdo con Driver, reaccionaron de la siguiente manera:

4 También Jiménez (1932: 21), Powell (1996: 48) y otros. 
We strongly suspect that most of the Chichimecs did not appove of the school teacher maping the location on their houses and the boun daries of their lands, and that they refused, to allow he ron their property to take me aserements and make other observations. This experience reflects the long history of encroachment on Chichimec lands by Spanish and Mestizos. Outsiders, such as our selves, Mexican Federal Government or ambitious and fishonest individuals likely to appropiate their lands (Driver, 1963: 171).

"A partir del proyecto y de las políticas posrevolucionarias, la comunidad hizo posible hacer oír sus demandas, entre las cuales se encontraba recuperar su territorio a través de un litigio de restitución de tierras; sin embargo, lo que se obtuvo tras este proceso fue una dotación de tierras, que fue lo que constituyó el ejido y que en un principio se otorgó a 143 familias" (Uzeta, 2004: 210-218). Este hecho fue decisivo en la vida comunitaria ya que, como veremos más adelante, instituyó nuevas autoridades y creó otros grupos en el interior de la comunidad.

Misión de arriba y Misión de abajo es la forma en que localmente se distingue a las dos partes de la comunidad, lo cual no sólo muestra una división física marcada en el territorio sino una serie de aspectos sociales que les separa y les diferencia. Uno de los principales aspectos de diferenciación entre las dos partes de la comunidad lo constituyó el acceso a la educación y a las políticas de castellanización emprendidas desde el clero y/o desde el Estado.

\section{Aspectos sociodemográficos 2.1 Lengua y población}

En 2010, en Misión de Chichimecas se registró una población de 6716 habitantes y 2011 hablantes de chichimeca-jonaz, lo que significa que sólo 30\% de la población es hablante de esta lengua perteneciente al grupo lingüístico otopame. En este grupo se ubican también: otomíes, mazahuas, matlazincas, pames y chichimecas (Soustelle, 1993: 13).

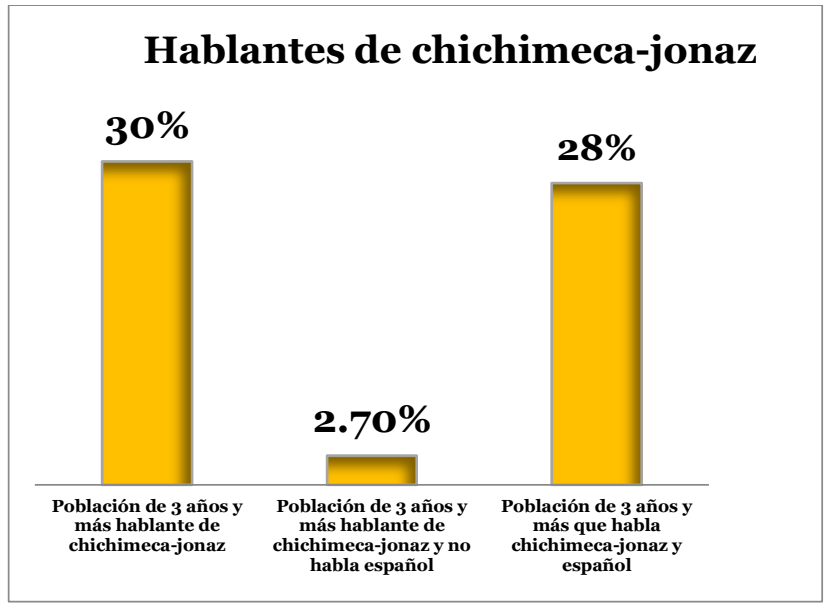

FUENTE: INEGI, Principales Resultados por Localidad (ITER), 2010.

A nivel nacional, el chichimeca-jonaz se localiza en la posición 39, en cuanto a número de hablantes en lengua indígena, con 2011 (CDI, 2010: 15). En el estado de 
Guanajuato, esta lengua ocupa el segundo lugar al mismo respecto, sólo antecedida por el otomí. La mayor parte de los hablantes de chichimeca-jonaz de esta entidad se localiza justamente en la comunidad de Misión de Chichimecas. Estando en el terreno, se pudo observar que esta lengua es principalmente hablada por niños y por personas de la tercera edad.

La primera escuela en la comunidad se instaló en Misión de abajo hacia el año de 1888 (Henríquez, 1999; 25), donde se impartía sólo el primero y segundo grados de primaria. Fue hasta 1973 que se estableció una primaria en la misma zona donde se impartían todos los grados. Por esta razón, en Misión de abajo la población que empezó a asistir a la escuela aprendió más rápido el español y sus habitantes pudieron relacionarse más fluidamente con el grupo mestizo que les marginaba por el uso de su lengua autóctona. Como resultado de estas políticas de castellanización, el habla en lengua indígena gradualmente se ha ido perdiendo en este fragmento de la población. El elemento racial entre los pobladores de la cabecera municipal fue un elemento de segregación y discriminación hacia la población originaria de Misión de Chichimecas, por lo cual la generación intermedia entre los hijos y los abuelos no habla el idioma.

Cuando era niño, mi papá no me dejaba hablar el idioma. Yo aprendí porque mis abuelos me hablaban el idioma y yo escribía las palabras en una libreta (Salvador, subdelegado de Misión de Chichimecas, 34 años).

En Misión de arriba se instaló una primaria hasta 1990 (Escuela Chupitantegua). En esta sección de la localidad también se ha demorado más la instalación de todos los servicios públicos. Éstos llegaron más pronto a Misión de abajo, por lo que actualmente es allí donde la población tiene mayor acceso a los mismos.

Se registró que, dentro del aula, el chichimeca-jonaz, a partir de la educación básica, sólo se enseña como una materia adicional a las ya establecidas; todas las clases se imparten en español.

Yo veo la influencia del INI en Tabasco, Oaxaca, Chiapas, para el impulso de las escuelas indígenas, y me pregunto, ¿̇por qué en Misión de Chichimecas no hay escuelas indígenas, donde se dé toda la clase en los dos idiomas? Aquí nada más hay una clase del idioma. Yo pienso que no hay escuelas indígenas porque no se sabía que existíamos nosotros, pensaban que Guanajuato era mestizo (Adrián, maestro hablante de chichimeca-jonaz, 43 años).

En términos demográficos, la comunidad de Misión de Chichimecas ha tenido un crecimiento importante ya que, de acuerdo con datos censales, en 1921 la comunidad contaba con 408 habitantes y tenía la categoría de rancho; pero, a partir de 1970, se empieza a visualizar un crecimiento importante de la población, hasta llegar a 2010, ya que de contar con 918 habitantes en 1970, en 2010 se registran 6716 habitantes (INEGI, 2010). 


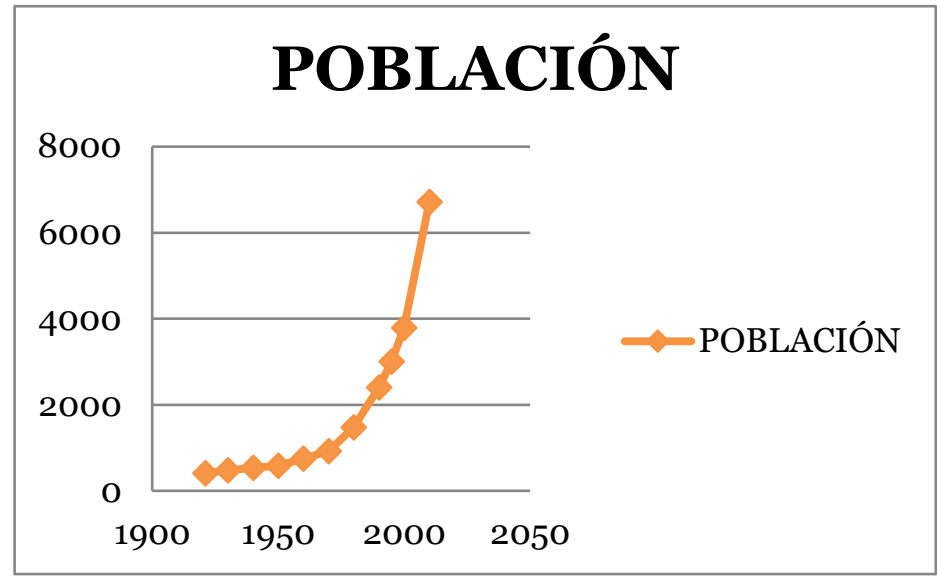

FUENTE: elaboración propia a partir de los resultados del INEGI en el rubro Principales resultados por localidad (ITER), 2010.

\begin{tabular}{|l|r|r|r|r|r|r|r|r|r|r|r|}
\hline \multicolumn{8}{|c|}{ CRECIMIENTO DEMOGRÁFICO DE MISIÓN DE CHICHIMECAS } \\
\hline AÑO & 1921 & 1930 & 1940 & 1950 & 1960 & 1970 & 1980 & 1990 & 1995 & 2000 & 2010 \\
\hline & & & & & & & & 2 & 3 & 3 & \\
POBLACIÓN & 408 & 475 & 535 & 585 & 750 & 918 & 1476 & 400 & 002 & 789 & 6716 \\
\hline
\end{tabular}

En 2010 se registra una población de 6716 habitantes, distribuidos por sexo de la siguiente forma:

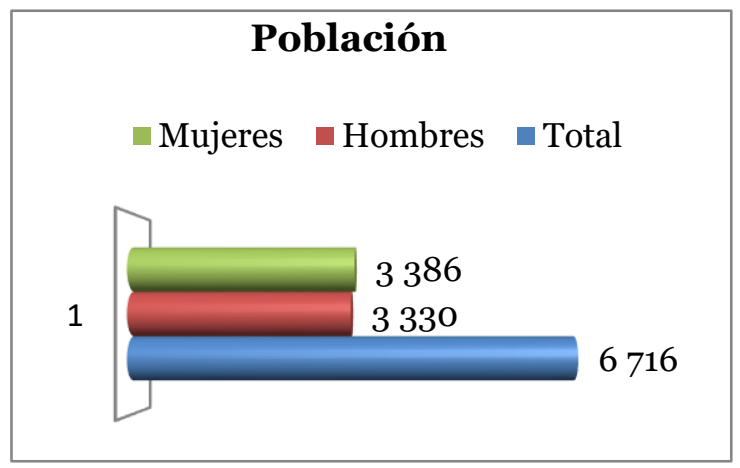

FUENTE: INEGI, principales resultados por localidad (ITER), 2010.

\subsection{Salud}

El maíz, el frijol y el nopal son alimentos esenciales en la dieta diaria de los habitantes de la comunidad. El maíz es el elemento que siempre está presente; por las mañanas, algunas familias acostumbran consumir un atole de maíz con chocolate al que llaman "atole de puscua", además de preparar tortillas hechas a mano durante la mañana para el consumo de todo el día. El frijol es preparado de diferentes formas; sea guisado, cocido o frito, siempre está presente en alguna de las tres comidas del día, así como el nopal. 
Recientemente se registra en la comunidad un cambio en los hábitos alimenticios, ya que se percibe un aumento en el consumo de refrescos embotellados y de otros productos "chatarra", lo cual ha propiciado un incremento en el padecimiento enfermedades como diabetes e hipertensión; el médico titular de la Unidad Médica de Atención Primaria a la Salud (UMAPS) refiere que en el lapso de 10 años aumentó considerablemente este padecimiento, ya que de cinco casos de pacientes con diabetes, el número se incrementó a 120 pacientes en control.

Respecto de la natalidad, el UMAPS señala que existe una tasa muy elevada, ya que se registran nacimientos de 7 a 13 niños por mes, debido al temprano inicio de la vida sexual entre los adolescentes. También se ha registrado un alto nivel de embarazos en adolescentes de entre 14 y 19 años.

En cuanto a la mortalidad de niños menores de 5 años, el médico local señala que existe una disminución a partir de 1995, año en el que se registró un alza en la mortalidad infantil a causa de enfermedades intestinales y respiratorias, ante lo cual el municipio y la comunidad implementaron varios programas para la disminución de este índice.

De acuerdo con la información recabada en entrevistas, antes de la llegada del Centro de Salud la mortalidad infantil era muy alta.

Yo tuve 14 niños, pero se me murieron seis, del sarampión. Fíjese: una de mis niñas, me acuerdo, ya estaba grandecita, tenía mucha calentura. Yo salí para traerle medicina. Cuando llegué, estaba sentadita, y luego nada más entró poquito aire y se me desmayó. Ya se me había muerto, nada más se me cayó así, como que suspiró y se me murió (Martha, habitante de Misión de arriba, 70 años).

En 1995, los informantes recuerdan que fue un año muy difícil para la comunidad. Además de que no se dieron las cosechas, se registraron temperaturas muy elevadas, lo que ocasionó la muerte de un número considerable de infantes.

En el 95, hubo un tiempo muy frío. Hubo muchas muertes de niños. Eso llamó la atención de cómo se vive en Misión de Chichimecas. El INI vio las necesidades de la comunidad (José, delegado de Misión de Chichimecas, 36 años).

Respecto de la morbilidad en la población infantil, se registran factores como la desnutrición, enfermedades gastrointestinales (principalmente diarreas), enfermedades respiratorias, infecciones de la piel e infecciones dentales.

En la población de adultos jóvenes de entre 25 y 45 años, se señala que la principal causa de muerte es el alcoholismo, que es un problema muy arraigado en la comunidad desde tiempos inmemoriales. Esto se registra en las siguientes cifras: "el $8.4 \%$ de los jefes de familia toman diariamente pulque, mientras que el $16 \%$ lo consume de 2 a 3 veces por semana; el tabaquismo fue positivo en un $51.1 \%$, además de que existen otras toxicomanías como el cemento, con una incidencia del 80\%, y la marihuana con un 20\%" (Martínez, 2008: 26).

En cuanto a servicios de salud, se registran 2298 personas sin derecho a algún servicio en este rubro, mientras que 4396 personas cuentan con algún tipo de servicio de salud, entre los cuales 94\% cuenta con Seguro Popular, mientras que 5\% cuenta con servicio del IMSS y 1\% con el del ISSSTE (INEGI, 2010). 
Aunada a los servicios de salud antes señalados, se encuentra la medicina tradicional, la cual, debido a su importancia, ha persistido en la comunidad a través de curanderos, parteras, yerberos, rezadores, etc., ya que hasta antes del año $2000^{5}$ era el único recurso para atender la salud de los miembros de la comunidad.

\begin{tabular}{|l|r|}
\hline Población sin derecho a servicios de salud & 2298 \\
\hline Población con derecho a servicios de salud & 4396 \\
\hline Población con derecho al IMSS & 219 \\
\hline Población con derecho al ISSSTE & 58 \\
\hline Población con Seguro Popular & 4140 \\
\hline
\end{tabular}

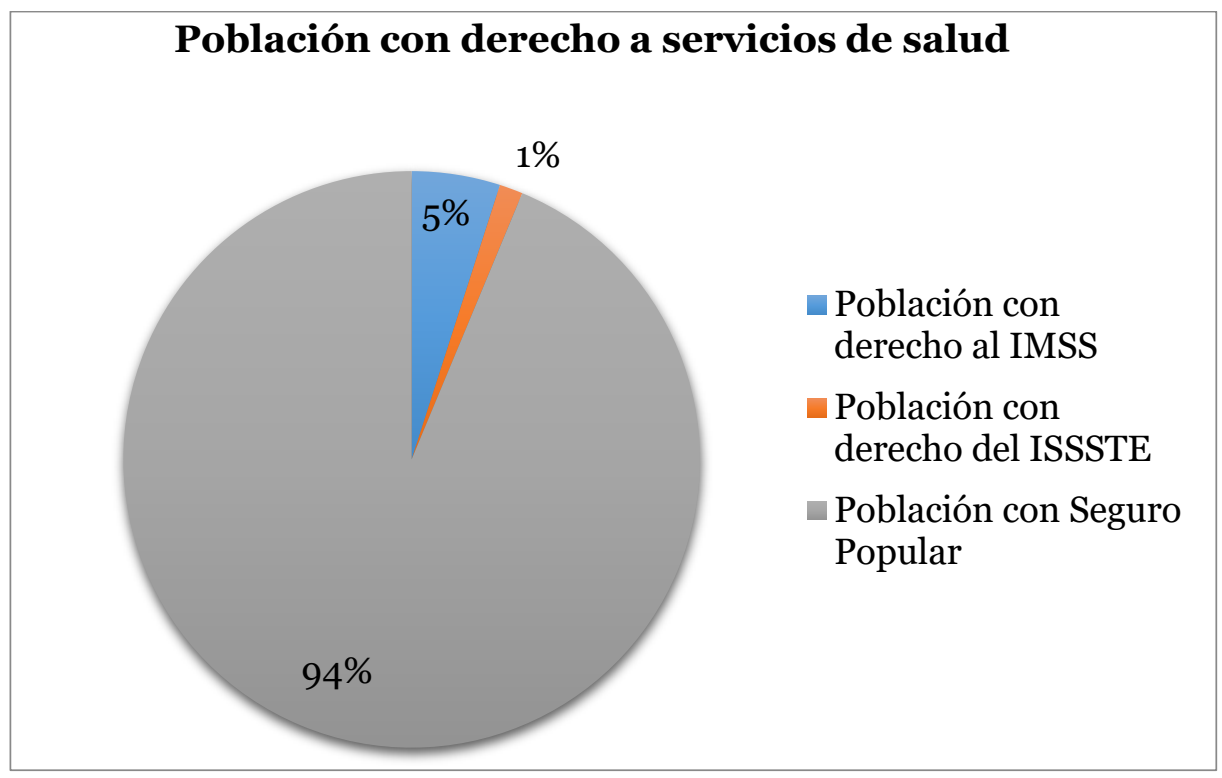

FUENTE: INEGI, Principales resultados por localidad (ITER), 2010.

\subsection{Infraestructura y servicios}

Desde la fragmentación de la localidad por la construcción de la carretera que va del municipio de San Luis de la Paz al municipio de Victoria, Misión de abajo es la parte más cercana a la urbe. Como arriba se dijo, aquí se instaló la primera escuela de la comunidad, en 1888, lo que contribuyó al más rápido aprendizaje del español y a incrementar la relación con los mestizos, de quienes quedaban al margen por el uso de la lengua indígena. Este patrón de desplazamiento de la lengua se repitió de forma interna en la comunidad, ya que en la parte de "abajo", al aprender el español, reprodujeron esta actitud discriminatoria hacia los de "arriba", donde todavía no se había aprendido el español.

Mi mamá sí lo admitió. Una vez dijo: “iYo no les enseñé la lengua a mis hijos porque no quería que sufrieran lo que yo sufrí!” Hubo mucha discriminación por parte de la gente de San Luis. Cuando oían que hablaban así, en la lengua, volteaban y los señalaban y se reían. Porque iban y hablaban un poco el español, no lo hablaban muy bien (María, habitante de Misión de abajo, 33 años).

5 Año en el que se instaló la Unidad Médica de Atención Primaria a la Salud (UMAPS). 
De la misma forma, los servicios se instalaron primero en la zona de "abajo"; allí es donde la mayor parte de las viviendas dispone de ellos en la actualidad. Ahí las construcciones son de mejor calidad y se visualizan menores indicios de marginación. La lengua autóctona se ha dejado de hablar casi en su totalidad, sólo algunas personas ancianas son las que la hablan.

Misión de arriba, en cambio, se encuentra más alejada de la urbe y presenta mayores índices de pobreza. En este lugar la mayoría de las personas hablan el chichimeca-jonaz. La primera escuela se instaló allí hasta 1990, y a este lugar han demorado más en llegar los servicios. Aquí no todas las viviendas disponen de todos los servicios públicos; todavía se conservan, en su mayoría, construcciones de adobe. Además, aunque en esta parte de la comunidad vive la mayor parte de la población, las viviendas se encuentran más dispersas y se ha tratado de mantener una distancia social más marcada con el grupo mestizo. Aquí se visualizan mayores índices de marginación.

En el aspecto de la organización comunitaria, estas diferencias hacen vislumbrar una fragmentación del sentido de unidad, pero ċqué sucede en la unidad mínima de organización: la familia? Más adelante abordaremos este problema.

Por lo que concierne al proceso de conurbación derivado del crecimiento de la ciudad de San Luis de la Paz, hay que decir que, además de varios programas implementados en la comunidad de Misión de Chichimecas, se ha logrado mejorar la infraestructura comunitaria a partir de 1990.

La comunidad cuenta con dos jardines de niños, dos escuelas primarias, una telesecundaria y un videobachillerato.

De los niños en edad preescolar de entre 3 y 5 años, 29\% asiste a la escuela; $78 \%$ de la población de niños de 6 a 11 años asiste a la escuela primaria, mientras que $77 \%$ de adolescentes entre 12 y 14 años asiste a la escuela y 33\% de los jóvenes de 15 a 17 años asiste a la escuela; sólo 5\% con edad entre 18 y 24 años asiste a la escuela.

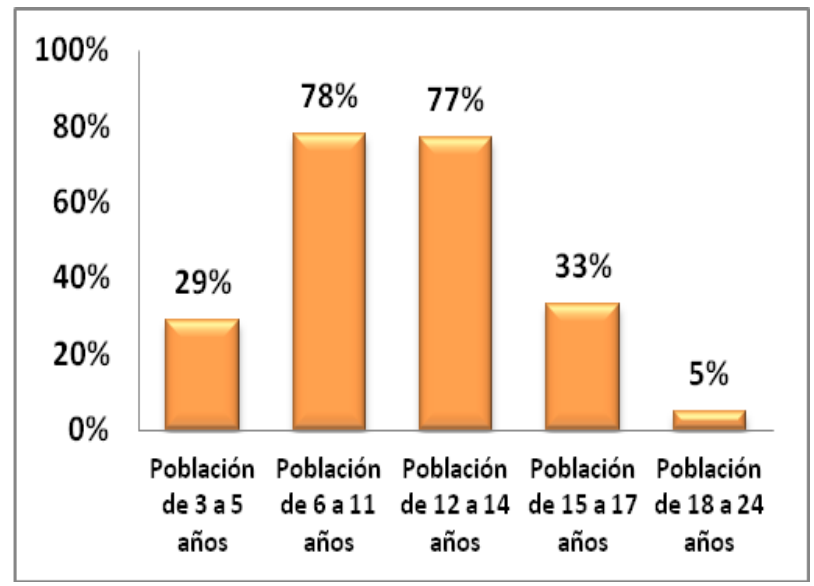

FUENTE: INEGI, Principales resultados por localidad (ITER), 2010.

Los jóvenes de la comunidad perciben la educación como una herramienta en la difícil lucha por deslindarse de la desigualdad social y lograr una mejora en la calidad de vida. De un total de 60 jóvenes encuestados en el videobachillerato de Misión de 


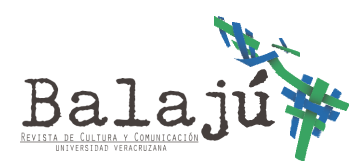

arriba, inscritos en la educación media superior, 76\% respondió positivamente a la idea de estudiar una carrera universitaria. Los principales motivos fueron: "Para tener un trabajo seguro y mejor" (Jimena, 15 años), "Para superarme" (Sergio, 15 años), "Para tener un mejor futuro" (José, 15 años), "Para ser alguien en la vida" (Nancy, 16 años), "Hallar un trabajo digno" (Israel, 17 años), "Quiero estudiar una carrera y sacar adelante a mi familia y apoyar a mis hermanos para que sigan estudiando" (Maritza, 16 años).

Lamentablemente, son pocas las oportunidades que los jóvenes tienen para estudiar y llegar a la universidad, ya que sólo 5\% de los jóvenes con edad entre 18 y 24 años asiste a la escuela.

\begin{tabular}{|c|c|c|}
\hline \multicolumn{3}{|c|}{ Grado promedio de escolaridad } \\
\hline Guanajuato & San Luis de la Paz & Misión de Chichimecas \\
\hline 7.73 & 6.76 & 4.6 \\
\hline
\end{tabular}

FUENTE: INEGI, Principales resultados por localidad (ITER), 2010.

En cuanto a servicios públicos, la comunidad cuenta con electricidad en gran parte de las viviendas, y con alumbrado público sólo en algunas áreas, como es el caso de las calles principales.

La mayoría de las viviendas cuenta con agua potable, proveniente de dos pozos perforados, la cual pasa por un proceso de cloración en una estación equipada para tales fines, instalada en Misión de abajo desde 1983.

Se cuenta, además, con otros servicios como Internet, telefonía fija, telefonía celular, servicios de computación, drenaje, etc., tal como se muestra más adelante en la tabla. El principal servicio de transporte lo constituyen los camiones colectivos o microbuses que dan servicio de pasaje de San Luis de la Paz a Misión de Chichimecas.

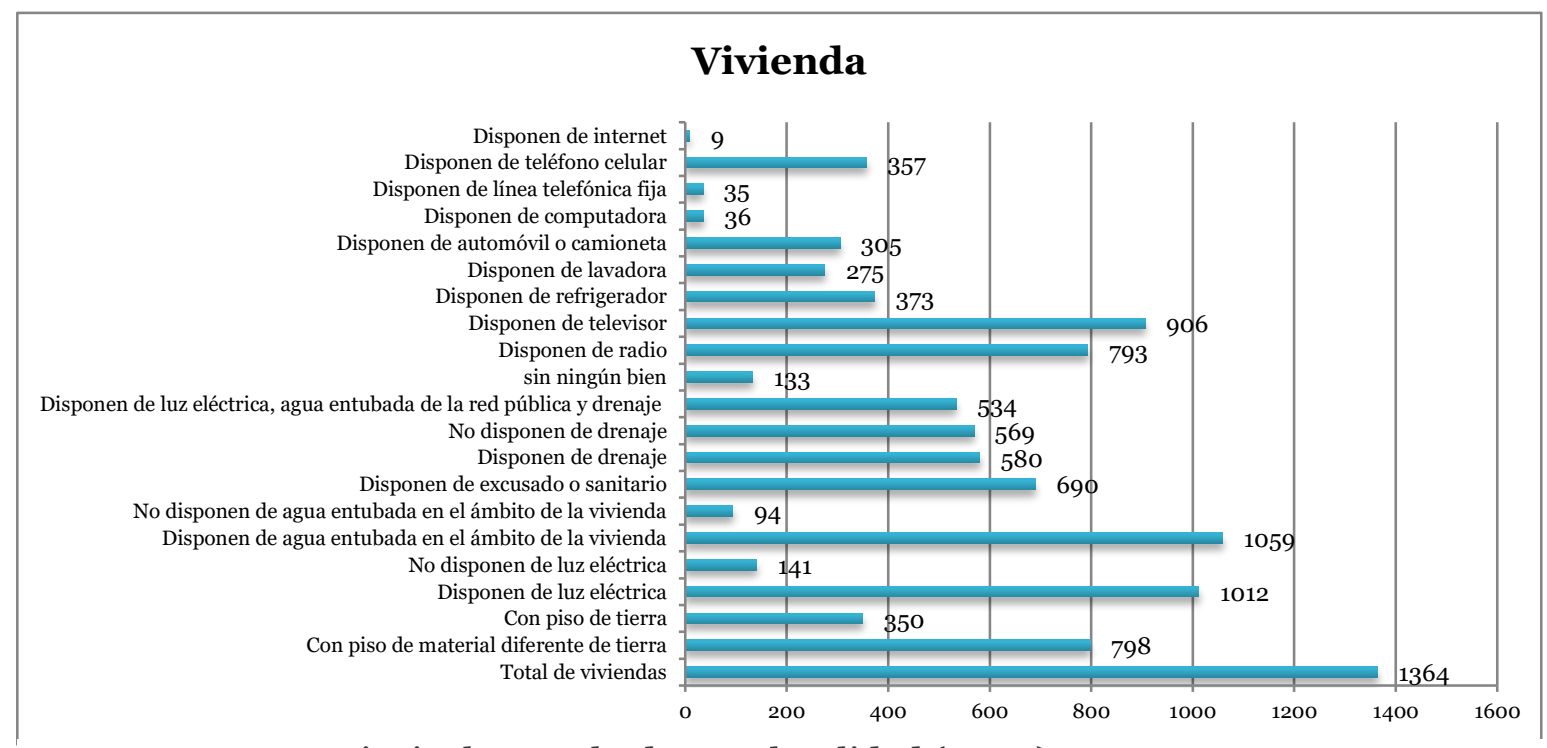

FUENTE: INEGI, Principales resultados por localidad (ITER), 2010. 


\subsection{Religión}

Estadísticamente, en la localidad se registra 96\% de la población como católica, religión impuesta en la comunidad, tras la reducción y asentamiento de los grupos nómadas que ahí se establecieron. En la actualidad, se observa un sincretismo en las prácticas religiosas, lo cual se manifiesta en las festividades más importantes para la comunidad como: el festejo de la Santa Cruz, el 3 de mayo; el festejo a San Luis Rey, el 25 de agosto; y la fiesta de la Virgen de Guadalupe el 11 de diciembre. En dichas festividades se realizan peregrinaciones en las que gran parte de la comunidad participa ofrendando danzas, comida y "el Chimalli” (Escudo de Guerra). Este último es una estructura de entre 3 o 4 metros, entretejida con la planta que le da el nombre a la ofrenda, la cual es una planta endémica de la región, de tipo cactácea, localizada en los cerros aledaños a la comunidad.

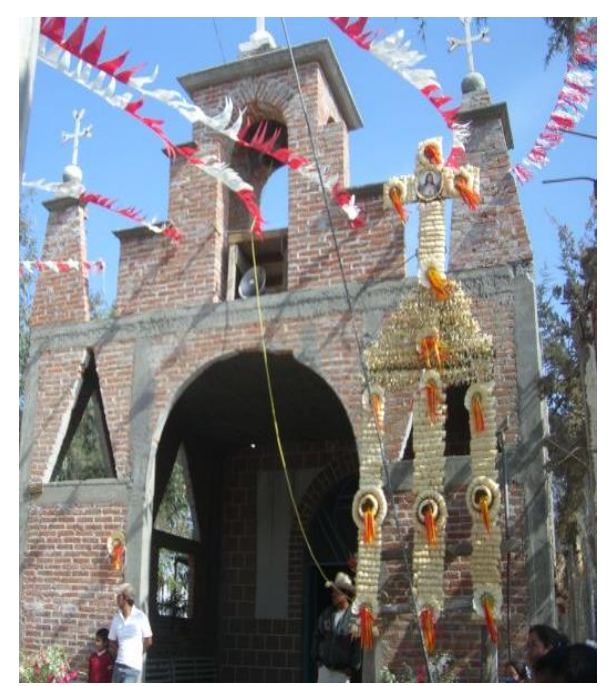

Fiesta de la Santa Cruz

Foto: Ana E. Villegas Ortiz, 3 de mayo de 2011.

La fiesta a San Luis Rey se celebra propiamente en el municipio de San Luis de la Paz, ya que es el santo patrono de la ciudad. El festejo incluye una feria, que se realiza en las dos últimas semanas de agosto; pero el día de la celebración es el 26 de agosto. En este día, la comunidad de Misión de Chichimecas participa mediante una peregrinación, que parte de la central camionera y llega hasta el templo de San Luisito. En esta peregrinación, las personas van con sahumerios y danzas acompañando su ofrenda para el santo, "el Chimal", la cual generalmente lleva la figura de un águila en la parte superior.

Este festejo de la comunidad chichimeca refiere el inicio de su vida sedentaria. Para ellos, San Luis Rey fue quien hizo posible el Tratado de Paz. Pero más que remontarse a la etapa de la conquista, para el imaginario de cierta parte de la comunidad chichimeca el Tratado de Paz se remonta a la etapa posrevolucionaria, ya que, de acuerdo con las entrevistas realizadas, fue una época muy marcada en la región por la revuelta social. A lo cual las poblaciones que eran tomadas, sea por un bando a favor o en contra de la revolución, eran las que realmente padecían a manos de "la bola". 
Cuando llegaban los carrancistas, nos escondían, porque se llevaban gente, se llevaban a las muchachas. Mi tía las vestía de viejitas para que no se las llevaran. No podían comer, porque todo les quitaban. Enterraban la comida y comían hasta la noche, para que no los vieran. Allá en el lote había mucho maíz sembrado. Los carrancistas llegaron y echaron ahí a los caballos. Nadie decía nada, porque si no lo mataban. La gente de aquí estuvieron viviendo en la Parroquia Grande, por eso tenemos a San Luis Rey, porque nada más corría la sangre. Él fue quien hizo las paces (Anastasia, habitante de Misión de abajo, 80 años).

En la comunidad, la fiesta en honor de la Virgen de Guadalupe (festividad, por cierto, que contribuye a fortalecer los vínculos de identificación entre los miembros de este grupo) se lleva a cabo en un recinto, en el cual hay una construcción en forma de escalinata, pintada de verde, blanco y rojo; en la cima de ésta hay una vitrina que contiene la imagen de bulto de la Virgen de Guadalupe y encima una cruz. Este altar o construcción se encuentra afuera de una casa, en donde generalmente se organiza la fiesta. En torno a esta festividad se desarrolla un importante sistema de cargos o mayordomía que se establece en cuanto a la organización de la fiesta.

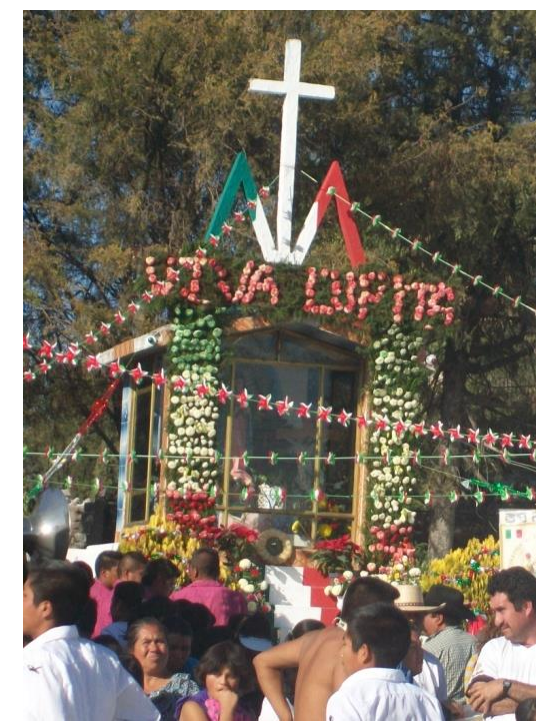

Fiesta de la Virgen de Guadalupe Foto: Ana E. Villegas Ortiz, 11 de diciembre de 2011.

Este sistema de cargos está integrado por varios hombres de la comunidad, a los cuales se les denomina "esclavos" de la Virgen. Para estos hombres, ser "esclavos" de la Virgen significa una responsabilidad y un compromiso vitalicios, ya que este cargo se hereda de padre a hijo (varón) o, en su caso, de suegro a yerno ${ }^{6}$.

-Aquí, los cargos se heredan. El papá de mi esposa era esclavo de la Virgen, y ya no puede ahora, porque esto es trabajo de hombres.

$-¿$ ¿La familia del esclavo participa?

\footnotetext{
${ }^{6}$ Esto sucede cuando el esclavo que hereda su cargo no tiene hijos varones o sus hijos no se interesan en participar ni en ayudar en las labores que conlleva ser "esclavo".
} 
-Depende de la edad del esclavo. Si es muy grande, manda a sus hijos cuando no puede ir al cerro, o les toca aportar dinero para comprar cuetes. Se apoya en sus hijos (Luz, esclavo de la Virgen, 43 años).

Los esclavos de la Virgen son alrededor de 35 personas organizadas por alguien que es la autoridad de los esclavos ("el más grande") y que se encarga de organizar las comisiones o diferentes actividades a realizar para la fiesta. Ésta da inicio desde el mes de julio, con una colecta de dinero que servirá para costear los gastos de la fiesta.

Entre otras actividades que realizan los "esclavos", se encuentra ir a buscar lugares específicos donde se encuentra la planta del Chimal. Parte de los "esclavos" se va desde el 8 de diciembre para recolectarla, mientras los demás se quedan en el patio del recinto de la Virgen, armando la estructura para la ofrenda. Ya cuando llega la planta, algunos se encargan de prepararla, es decir, de pelarla y despencarla. En esta actividad también participan personas que no son "esclavos", pero que se ofrecen para ayudar, ya que desde que se empieza a armar la estructura, a preparar la planta y a tejerla en la estructura de madera no se para de trabajar ni aun en la noche. Esto implica también que haya personas encargadas de preparar la comida para los "esclavos", que generalmente son las esposas de los esclavos o mujeres devotas de la Virgen de Guadalupe que tienen como penitencia participar en los preparativos de la festividad.

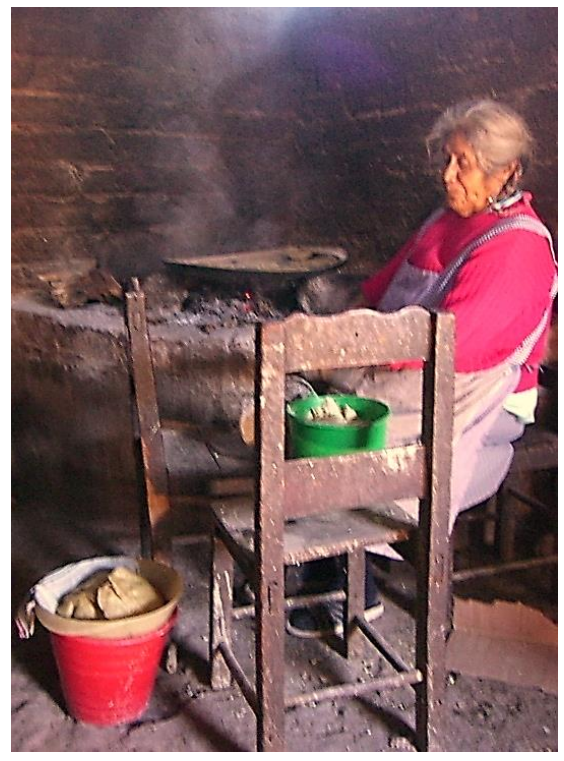

Preparación de los alimentos para la fiesta.

Foto: Ana E. Villegas Ortiz, $11 \mathrm{de}$ diciembre de 2011. 


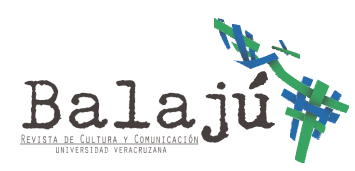

El día 10 de diciembre se sigue trabajando y un grupo de "esclavos" acompañado de varias personas de la comunidad se encargan de recorrer varias casas durante la noche. A esta actividad se le denomina "juntar la cera" y consiste en ir a traer una vela de grandes dimensiones para la Virgen. Esta actividad concluye en la madrugada. Para el día 11 de diciembre ya la ofrenda debe estar terminada, dado que, antes de llevarla al Santuario de Guadalupe en el municipio de San Luis de la Paz, se le danza, reza, "sahúma", se ofrece comida y música en la comunidad, para después llevarla cargada a cuestas de los "esclavos", en una peregrinación presidida por los diferentes grupos dancísticos que se han formado en la comunidad, además de varios asistentes. Ese día, en el santuario les espera el sacerdote para recibir la ofrenda y colocarla en la entrada del templo, en el cual se oficia una misa dedicada a la comunidad de Misión de Chichimecas.

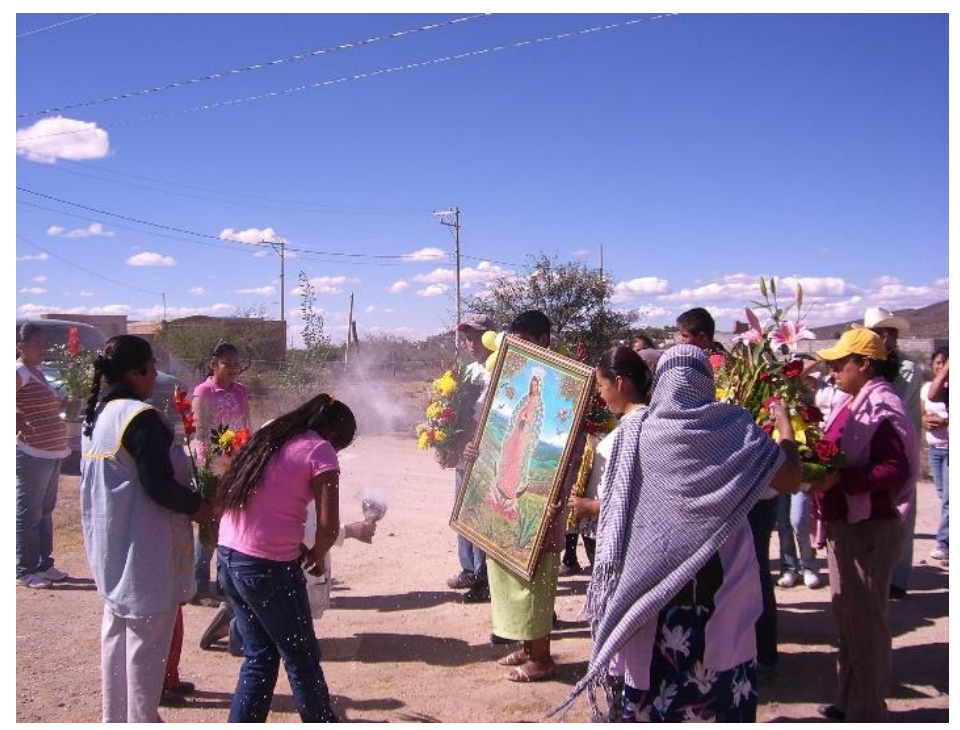

Recibimiento y sahumerio de la imagen de la Virgen de Guadalupe.

Foto: Ana E. Villegas Ortiz, 28 de octubre de 2011.

La devoción manifestada en esta festividad, además del cuidado en la organización y en los preparativos, que se concretan en la mayordomía de "los esclavos" de la Virgen, hacen que esta festividad sea la más representativa para la comunidad, ya que, al parecer, esta ferviente devoción pudiera tener sus antecedentes en la formación histórica de la comunidad, ya que cuando se funda San Luis de la Paz, "se fundó así el pueblo, dividido en cuatro barrios y una zona no indígena" (García, 1891: 23).7 El barrio donde se asentó la población chichimeca se denominó Barrio de Guadalupe. Además, algunas fuentes coinciden en el sincretismo existente entre el culto al dios Curi-caberi y la ferviente devoción hacia la virgen de Guadalupe, ya que "según la tradición oral, en la época precolombina, en el cerrito donde se ubica el Santuario de Guadalupe, los chichimecas tenían un adoratorio a Curi-caberi, su dios del agua y del fuego" (García, 2005: 2), elementos que en la actualidad dan pautas para entender las manifestaciones religiosas en la comunidad.

7 Antonio García Cubas, citado por Rabell (1986: 23). 


\title{
3. Organización político-administrativa
}

Las formas de organización de la autoridad dentro de la comunidad oscilan entre lo tradicional y lo formal. Por un lado, el sistema de autoridad está integrado al del municipio mediante el reconocimiento oficial de la figura del delegado como máxima autoridad, y la del subdelegado como segundo al mando. Las personas de la comunidad recurren a estas figuras ante cualquier situación que requiera de un intermediario para solucionarse. Esta modelo parece estar estrechamente relacionado con la figura de autoridad que existía antes de la del "delegado". Dicha figura era el "reconocido como cacique o patriarca de la comunidad, a quien se pide consejo y autorización para todos sus actos" (Uzeta, 2004: 220). Driver (1963: 174) relata que esta autoridad se encargaba de mantener el orden de la comunidad por medio de ciertos tipos de castigo en los que, si se consideraba que se ofendía a la comunidad, toda ésta participaba castigando al ofensor.

\begin{abstract}
When a boy has been seriously delinquent, everyone in the Chichimec assembles at is house to join a program of punishment, ridicule, and advice for the better. The boy stands in the center of the room, the old man sit down around him in the house, and other people crowd into the house or gather outside in the yard. The boy's pants are removed and each adult person in turn switches the boy lightly on the buttocks, as much to shame as to hurt him, and says to him: "Do you understand?"... No one eats until the affair is terminated, both because they are emotionally disturbed and to impress the ofender with the seriousness of his offense (Driver, 1963: 174).
\end{abstract}

Durante la dotación de tierra y la formación del ejido en la etapa posrevolucionaria, este cacique o patriarca fue sustituido en el peso de su autoridad por el comisariado ejidal, ya que la organización comunitaria, a partir de la dotación de tierras, giró en torno al ejido y sus aspectos políticos: "La experiencia resultó tan relevante que la estructura ejidal fue minando la representatividad de las autoridades tradicionales, justamente porque éstas carecían de capacidad de intermediación con las instituciones estatales, por lo que durante la época de auge del ejido (1940-1970) el Comisariado Ejidal fue concebido como la máxima autoridad dentro de la comunidad" (Uzeta, 2004: 203). En la actualidad, la figura del comisariado ejidal existe, pero sólo como una autoridad agraria encargada de atender lo referente a asuntos relacionados con el ejido.

Hoy en día, en la comunidad se conforma una estructura sociopolítica representada por las siguientes figuras:

- El Delegado y el Subdelegado

- El Comisariado Ejidal

- El Comisariado de Bienes Comunales

- El Consejo Indígena

El Delegado y el Subdelegado se eligen por medio de un acuerdo común mediante una asamblea en la que participa toda la comunidad. En esta asamblea, las personas pueden proponer a quien consideran un buen líder o alguien se puede autonombrar como candidato para el cargo, ante lo cual la comunidad emite su acuerdo o desacuerdo. Es importante señalar los elementos que se toman en cuenta para la elección del representante de la comunidad, ya que se considera relevante la 


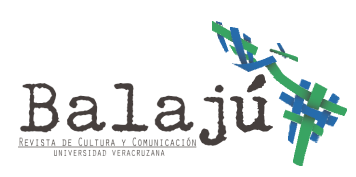

conducta de la persona en su vida cotidiana y el que sea una figura de "respeto" dentro de la comunidad. En la elección no se consideran elementos formales tales como el grado de escolaridad, sino la observancia de una buena conducta y el interés por resolver los asuntos de la comunidad.

El Comisariado de Bienes Comunales es la autoridad de un Consejo que se formó como resultado de la modificación al artículo 27 de la Constitución y con la entrada en vigor del Programa de Certificación de Derechos Ejidales y Titulación de Solares (Procede) en el estado de Guanajuato, a partir del cual se dio una venta indiscriminada de terrenos dentro de la comunidad. Este novedoso hecho resultó preocupante para algunas personas de la comunidad, ya que implicó la entrada de nuevas personas, instancias y procedimientos dentro de la misma.

Por lo anterior, la función del Consejo, en el que la máxima autoridad es el Comisariado de Bienes Comunales, era poner un freno a la venta de terrenos, ya que se estaban vendiendo terrenos deshabitados que habían pertenecido a personas que habían fallecido sin tener familia a quien heredar (terrenos que anteriormente la comunidad concebía como de uso común). En este escenario, el Comisariado se encargó de vigilar que los terrenos fueran utilizados en beneficio de la comunidad.

Ahora bien, en la comunidad existen varios tipos de propiedad, que se constituyen en:

- Propiedad Ejidal

- Propiedad Comunal

- Pequeña Propiedad Privada

- Avecindados

La propiedad ejidal ("el ejido") se formó a partir de las políticas posrevolucionarias. En la actualidad, el ejido se conforma por tierras de temporal y, en pequeña escala, por tierras de riego. Factores como las bajas temperaturas (heladas) características de la región y la escasez de lluvias propician una producción de autoconsumo por parte de las familias ejidatarias. Otra forma de aprovechar la tierra es de forma indirecta, a través de la usura o del préstamo de la tierra a cambio de una fracción de la producción de la cosecha.

La tierra se divide en surcos. En la parte de la tierra que es de regadío, cuando se siembran diez surcos, dos son para el ejidatario y las restantes para quien se le presta la tierra. Si el terreno es de temporal, un surco es para el ejidatario y los restantes para quien siembra (Luciana, ejidataria, 70 años).

Geográficamente, el ejido se ubica a unos cuantos kilómetros de la comunidad, por lo cual algunas familias procedentes de ésta se han instalado en parte del ejido, formando una colonia denominada Plan Juárez, con el objeto de evitar el traslado constante de la comunidad al ejido durante el tiempo de la preparación de la tierra, la siembra y la cosecha.

Como ya se señaló anteriormente, la Propiedad Comunal la constituyen los terrenos que no tienen dueño y que tienen la viabilidad de usarse en beneficio de la comunidad.

La Pequeña Propiedad Privada son propiamente los terrenos de cada familia, los cuales fueron categorizados como privados a partir de la titulación de terrenos 
por medio del programa Procede, ya que antes de éste las familias se ostentaban como posesionarias de sus tierras, para después pasar a ser propietarias de la misma.

La figura o concepto de Avecindados surge como resultado de la titulación de terrenos a través del programa Procede y de la venta de los mismos a personas fuereñas, que fueron denominadas como "avecindados". La mayoría de las personas que se han establecido en Misión provienen del municipio de San Luis de la Paz, de Victoria, Xichú, de algunas rancherías cercanas y de ciudades como México o Guadalajara.

El Consejo Indígena se formó en 1995 con 12 personas, tras el alto índice de mortalidad infantil ocurrido entonces a consecuencia de enfermedades respiratorias provocadas por las bajas temperaturas. En ese momento se tuvo el objetivo de tomar conciencia acerca de las condiciones de vida en las que se encontraban las familias, así como de emprender acciones con el fin de que el municipio se involucrara en el compromiso con programas públicos que beneficiaran a las familias en el mejoramiento de su calidad de vida. Ahora el Consejo Indígena se ha constituido como una asociación civil, y sigue con la mayoría de los miembros con que se fundó, fungiendo como un importante grupo de intermediación entre la comunidad e instituciones municipales y estatales, ya que a través del Consejo de Desarrollo Indígena (CDI) y del municipio han logrado implementar algunos proyectos que tienen el objetivo de propiciar el desarrollo económico de las familias.

Además, se ha logrado también una mayor participación política respecto al reconocimiento de las comunidades indígenas en el estado de Guanajuato ya que, a través del Consejo Indígena, en 2010 se logró un Foro de Consulta sobre la Aprobación de la Ley Indígena, cuya propuesta fue hecha por el Poder Legislativo del estado de Guanajuato. En este foro se logró discutir temas de interés para las poblaciones indígenas en el estado y también se establecieron los lineamientos para desarrollar un Padrón de Comunidades Indígenas en el Estado de Guanajuato, con el objetivo de identificar los núcleos de población indígena en el estado, buscando garantizar un mayor compromiso del gobierno estatal con las comunidades indígenas. En este foro se discutieron temas como la Educación Bilingüe y Cultural, Vivienda, Migrantes, Territorio, Representación Indígena, etc. A través de dicha consulta, pudieron observarse varias de las problemáticas que enfrentan las comunidades indígenas en la actualidad, como la falta de calidad en las viviendas, la falta de atención hacia los migrantes, la discriminación de que son objeto las comunidades, la falta de legislación laboral que existe en las industrias que llegan a instalarse en las comunidades, etcétera.

\section{Organización familiar y parentesco}

En el análisis de la organización social, cabe destacar la importancia de la red de relaciones entre las unidades que conforman la estructura de una sociedad determinada. De esta forma, "la familia es el ejemplo más obvio de una institución formada por un conjunto de papeles mutuamente dependientes y complementarios entre sí" (Burke, 1992: 60) y es la unidad más simple de organización social que guarda una estrecha relación con la estructura social. Las formas en que se han constituido las familias y sus relaciones de parentesco han sido constituidas de diferente forma de acuerdo con el contexto social, pero tienen en común ser el ámbito social primario donde se reproducen, desarrollan y relacionan los individuos. 


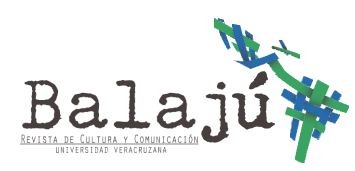

Varios escritos se han enfocado en señalar la transición de la familia extensa hacia la familia nuclear en el contexto urbano de las sociedades modernas. Este argumento ha sido ampliamente discutido, ya que se ha encontrado que en el contexto moderno, bajo condiciones de marginalidad, el tipo de familia que se desarrolla es la familia extensa, pues es a través del reforzamiento de lazos familiares como se desarrollan mecanismos de reciprocidad que permiten enfrentar situaciones precarias.

En el contexto de las comunidades indígenas se ha señalado la importancia del parentesco, ya que la familia no es sólo una unidad mínima de organización aislada sino que, a través de las relaciones de parentesco que se constituyen por afinidad, consanguinidad o a través del ritual (compadrazgo), las familias se articulan a otras unidades domésticas que constituyen unidades de organización más amplias, y que repercuten en las esferas de lo económico, lo político o lo cultural, tal como los sistemas de cargos cívico-religiosos, la conformación de barrios, la estructuración de las relaciones de poder, etc. Es en este sentido que "el estudio del grupo doméstico se ha dado a través del análisis de la intersección e interdependencia funcional entre el sistema de parentesco y las demás esferas de la vida" (Rowland, 1993: 33).

Misión de Chichimecas, como ya se indicó, tuvo sus orígenes como comunidad durante la Conquista, tras las políticas de la reducción y congregación de indios "que dio como resultado una forma particular de organización sociocultural y política que estableció las bases de lo que hoy denominamos comunidad indígena" (Tejera, 1993: 194). La comunidad, pues, tiene como base a la unidad doméstica, espacio social donde se producen, reproducen y transmiten elementos de la identidad.

En la comunidad, la costumbre dictaba que las unidades domésticas se conformaran generalmente por familias de tipo extenso; se integraban a partir de que los hijos varones concertaban el matrimonio y llevaban a vivir a sus esposas a la casa de sus padres. La concertación del matrimonio se llevaba a cabo a través de una tercera persona con algún tipo de autoridad como el sacerdote o el delegado. El matrimonio recién formado, después de un tiempo, procedía a construir su vivienda alrededor del solar de la casa, que por lo general es un terreno extenso en el que las construcciones van formando un rectángulo 8 y en el centro un patio compartido. En estas unidades se reconoce al padre de edad avanzada como la autoridad de la familia. Las actividades económicas se dividían por edad o sexo y eran compartidas por los miembros. Estas actividades estaban enfocadas primordialmente en el trabajo agrícola.

Para la elección del cónyuge, se daba preferencia a los miembros de la misma comunidad, ya que socialmente no era aprobado el casarse con personas fuereñas:

Antes se cuidaba mucho la mezcla (de sangre), se veía mal a quien se casara con alguien de fuera. A partir de los ochenta, eso cambió, las muchachas se casaban con muchachos de La Ciénega, del Paso... Salieron a trabajar fuera, a León, a Querétaro. Cuando regresaban ya venían con su esposa, y decían que se podían casar con otros y no sólo con los de Misión. Esto influyó para que se dejara atrás la pureza de sangre (Aurelio, habitante de Misión de abajo, 40 años).

\footnotetext{
${ }^{8}$ Véase los anexos.
} 
A quien contravenía esto se le reprochaba socialmente, y la pareja no quedaba exenta. Generalmente, quienes se casaban con personas de fuera eran hombres que salían a otras ciudades a trabajar, que conocían a una mujer y la llevaban a vivir a la comunidad. Por lo anterior, la costumbre dictaba matrimonios endogámicos, que permitían el mantenimiento, el reforzamiento y la configuración de redes sociales en el interior de la comunidad.

Remedios nos da su experiencia respecto de estar en la categoría de quienes no pertenecen al componente racial. Es una mujer viuda, originaria de Xichú, huérfana de padre a los 7 años, que se mudó a San Luis de la Paz con su mamá a los 17 años, con el fin de laborar como trabajadora doméstica.

Después de que me casé, me fui a vivir en un terreno donde vivían muchos hermanos de mi esposos, pero teníamos muchos disgustos porque yo no era de aquí, y sus esposas sí eran de la Misión (Remedios, 63 años).

El patrimonio de las unidades domésticas se constituye por lo general en la propiedad privada que conforman la casa y las parcelas del ejido. Las viviendas por lo general son construcciones de adobe con techo de lámina. Las familias van construyendo sus cuartos alrededor del solar de la casa de los padres y comparten un patio que utilizan para poner un fogón, además de ser un espacio para la crianza de animales y para tener pequeños huertos de hortalizas y de flores. En el tiempo del levantamiento de la cosecha, en este espacio se seca el maíz y el frijol, que son los principales productos que se siembran y se consumen a lo largo del año, por lo que se desgranan y se acumulan en un cuarto que se construye específicamente para este fin.

Por otra parte, "el ejido constituye un área de 3,600-72-oo hectáreas" (CIESAS, 2001: 1) conformado por parcelas que se dividen en calidad de pastoreo, riego y temporal. Este patrimonio era trasladado de padre a hijo, puesto que el hijo mayor tenía derecho a heredar las parcelas del ejido que le corresponden al padre, mientras que la casa de los padres se destinaba al hijo menor, y el solar se dividía entre los demás hijos varones casados.

Hasta aquí se presentan algunos rasgos generales en cuanto a cómo se constituyen tradicionalmente las unidades domésticas en la comunidad. Algunos de estos patrones se han ido modificando, ya que se han desarrollado cambios en otros aspectos de la vida comunitaria que han tenido posibles implicaciones en la familia chichimeca. Con base en lo descrito anteriormente, se proponer interpretar este proceso de cambio no como una transformación que proviene desde la misma comunidad tradicional, sino desde elementos promovidos por la intervención de factores externos. Principalmente la migración rotativa e internacional, así como el desmantelamiento del estado de bienestar y la reducción patrimonial del territorio chichimeca han repercutido en la organización interna de las familias, lo que deriva en la disociación en la distribución territorial de los grupos de parentesco constituidos a través de unidades domésticas ligadas por los usos y costumbres (virilocalidad inicial), lo cual implica un nuevo patrón residencial de las unidades familiares. 


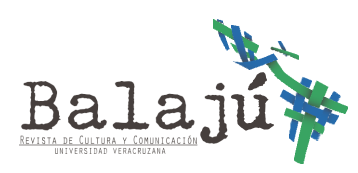

\section{Sobre identidad, desarrollo y proceso de cambio}

En la antropología, el término identidad es fundamental para el análisis de procesos de cambio como los que aquí se han descrito. La identidad es un elemento relacional de "otredad"; es esencial para comprender los procesos a través de los cuales un grupo determinado se identifica y adquiere elementos de pertenencia, para comprender qué le permite tener una representación de sí mismo a través del entramado cultural, ya que "la cultura proporciona significado a la experiencia humana, seleccionándola y organizándola de tal forma que le permite a las personas arraigarse a ciertos elementos que le dan sentido a su vida" (Rosaldo, 1991: 35). Esta afirmación nos lleva al planteamiento de Giménez (2001: 55), quien señala la diferencia entre las identidades "internamente" definidas y las identidades "externamente" imputadas, ya que mientras las primeras se construyen mediante las representaciones subjetivas en el ámbito interno del grupo, las identidades imputadas pueden entenderse como aquellas representaciones mediante las cuales este grupo es percibido por un conjunto de actores externos.

Tal como nos interesa subrayar en este escrito, lo anterior puede ser aplicado a la relación entre el Estado y las poblaciones indígenas, ya que a través de las políticas posrevolucionarias se inició una serie de programas destinados a modificar los elementos que definían internamente a estas poblaciones, con el fin de homologarlas con el resto del país.

En ese entonces, el Estado percibía la cultura de estos grupos como instalados en un estatus de "atraso" que impedía lograr el desarrollo nacional, por lo que, a través de diversos mecanismos, se trató de modificar ciertos elementos de estas poblaciones y conservar aquellos que le permitieran alimentar la construcción de un imaginario del pasado prehispánico glorioso de la nación.

En México, a partir del siglo XX, el "desarrollo" se ha concretado en la alineación al modelo neoliberal; si bien ello tiene un trasfondo económico, las implicaciones políticas y culturales que impulsa derivan en la homogeneización de las sociedades bajo los cánones de la modernización, "promoviendo un desarrollo lineal que supone que la modernización de los grupos tradicionales sólo puede ser inducida desde fuera y desde el centro" (Giménez, 1994: 115). A continuación, se señalan algunos elementos que se han implementado en la comunidad bajo las promesas del desarrollo.

Como ya se señaló, el ejido se constituyó tras las políticas posrevolucionarias hacia 1928. Uzeta (1996) señala que este hecho fue trascendente para la comunidad, ya que "la organización comunitaria se supeditó a los vaivenes políticos del propio ejido", además de que las figuras tradicionales de autoridad9 fueron sustituidas por el Comisariado Ejidal, ya que carecían de la capacidad de intermediación entre el ejido y las instituciones agrarias. Esto creó liderazgos en la comunidad en torno a ciertas familias con las que estaba emparentado el Comisariado y que sabían leer y escribir, lo que en ese tiempo era poco usual en la comunidad, por lo que se dieron ciertas tendencias de caciquismo ante el reparto desigual de los recursos destinados a la producción agrícola.

Posteriormente, hacia los años setenta del siglo XX, en la comunidad se implementaron algunos proyectos productivos para promover el desarrollo

9 El juez y el consejo de ancianos. 
económico. Tales proyectos eran implementados bajo diversos marcos teóricos para sustentar planes de desarrollo acordes a los ideales de la modernidad. El evolucionismo proponía los ideales de "progreso y civilización”. De igual forma, la visión funcionalista aportó qué se tenía que hacer para que las sociedades no occidentales fueran integradas al sistema capitalista, a través del conocimiento de las partes de la sociedad y su función, con el fin de sustituir las instituciones de la sociedad no capitalista y no causar desajustes dentro de la cultura que desembocaran en revueltas contra la sociedad integradora. A su vez, el culturalismo pretendía una visión de las sociedades no capitalistas con un respeto que permitiera el libre desenvolvimiento de cada una de ellas. Aguirre Beltrán (1992) aborda el concepto de "aculturación”, el cual define como "el proceso que emerge de grupos que participan de culturas diferentes” (Aguirre Beltrán, 1992: 19).

La política nacional de la "integración” fue desplegada a través del Instituto Nacional Indigenista (INI). Dicha institución definía la "integración" como "un conjunto de actitudes, con las cuales se ha logrado que gran parte de la población se reúna bajo la conciencia de una sola cultura, de una sola lengua y lo que es esencial de una sola nacionalidad" (INI, 1970). Mediante este proyecto de integración se intentaba "modificar la mentalidad 'mágico-religiosa' de las comunidades indígenas hacia una actitud 'científica' ante el mundo contemporáneo" (Caso, 1958: 11). De este modo se buscaba implementar técnicas de cultivo que propulsaran la eficacia de la producción agrícola y, por lo tanto, el desarrollo económico que presuntamente traería, por añadidura, el desarrollo social y cultural de las comunidades que entonces eran consideradas atrasadas e incapaces de integrarse al modelo de desarrollo nacional en el que se había enganchado el país tras adoptar el modelo neoliberal.

Como parte de este mismo proyecto en el ejido, se implementó el sistema de riego y un establo de vacas lecheras, que después de un tiempo fracasaron. En la actualidad el establo ha desaparecido y en el ejido se desarrolla una producción de autoconsumo, ya que las mejores tierras con sistema de regadío son rentadas a personas fuereñas que se dedican a la producción agrícola.

Una política que pretende integrar a los mismos grupos que considera subalternos se traduce en una contradicción desde la misma concepción del Estado, figura político-administrativa que detenta el monopolio del uso legítimo de la fuerza y que se contiene en un territorio determinado. Etnia y nación comparten un mismo contenido, la apropiación simbólica del territorio, así como una lengua compartida. Para Oommen (1997: 56), "el territorio cultural junto al lenguaje es la condición mínima para la existencia de la Nación”.

"La etnia es una Nación desterritorializada, una comunidad cultural disociada real o simbólicamente de su territorio, por desplazamiento forzado, despojo o la legislación basada en su relación con la tierra en términos instrumentales y no en términos simbólico-expresivos" (Neira, 2006).

Es así que algunos de los cambios más recientes en lo que concierne a la tenencia de la tierra se registran a partir de la entrada del programa Procede, hecho que ha contribuido, entre otros aspectos, a la desterritorialización progresiva en la comunidad. Este programa se instauró en 1990 aun sin el consenso de toda la comunidad, lo cual vino a crear facciones internas entre quienes estaban a favor y quienes estaban en contra. Algunas de las consecuencias de este programa fueron el 


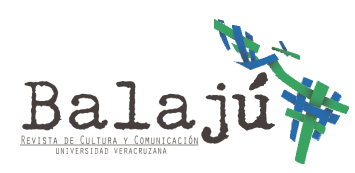

cambio de tenencia de la tierra, ya que las personas pasaron de ser posesionarias a ser propietarias de la tierra; cada persona tuvo un título de tierra, por lo que se dio la venta de terrenos de la comunidad a personas fuereñas (a las que se denominó avecindados) y también se instaló una maquiladora con el apoyo del municipio, bajo el argumento de propiciar empleos en la comunidad y así evitar el desplazamiento migratorio hacia Estados Unidos.

\section{Reflexiones finales}

Concretando en cuanto a la organización social, los factores externos que han incidido en posibles cambios en la comunidad de Misión de Chichimecas se resumen en el establecimiento del ejido tras las políticas posrevolucionarias y los programas implementados por instituciones externas que se han traducido en una distribución desigual de los recursos, principalmente por una relación dicotómica entre etnia y Estado. Esto ha promovido facciones dentro de la comunidad. Bajo el mismo modelo, los cambios en la tenencia de la tierra, la instalación de industrias en la comunidad, además del aumento de los índices de migración representan algunos elementos que se han venido dando a la par del proceso de políticas de desarrollo en la región.

Así, pues, en cuanto a organización social, Misión de Chichimecas se presenta como una comunidad fracturada, en la cual desde dentro se hace una diferenciación de un arriba y un abajo, referente que expresa la cicatriz que han dejado desde fuera, en el territorio y en la cultura, la implementación de políticas integracionistas inducidas por procesos políticos, sociales y culturales, así como la disolución de lo que se considera como propio. Este estado de cosas es representado eficazmente por la carretera, la cual aparece como un símbolo de la modernidad que fracturó física y culturalmente a la comunidad en dos: Misión de arriba y Misión de abajo.

ARRIBA $\rightarrow$ indígena, marginación

CARRTERA $\rightarrow$ fracturación, modernidad

$\mathrm{ABAJO} \rightarrow$ asimilación, mejor índice de calidad de vida

Esta división se relaciona a la vez con el uso y desuso de la lengua materna, así como con el hecho de lo que significa ser indígena para la sociedad mexicana.

Pues dicen que allá arriba es más indígena, allá hablan más la lengua (Laura, costurera habitante de Misión de abajo, 56 años).

En el ámbito de la organización familiar, los cambios refieren que parte de las familias que vendieron sus terrenos a partir de la entrada del programa Procede redujeron en gran medida su patrimonio territorial, por lo que se está modificando la distribución del grupo doméstico y su reproducción. Dado que no hay tierra para que se puedan asentar las nuevas parejas, se rompen los patrones tradicionales de la herencia y se obstaculiza la continuidad del grupo doméstico ubicado en un mismo asentamiento territorial. Este fenómeno se ha observado entre las parejas más jóvenes de la localidad que, al no contar con propiedades, han optado por cohabitar la casa de la familia de la novia. Se observa entonces una gradual pero importante transformación en los patrones de residencia propios de este grupo indígena, lo cual 
condice con lo señalado por Vaughan: "la crisis del sistema familiar mesoamericano se debe al debilitamiento del orden patriarcal de la familia patrivirilocal y extendida”, lo cual, de acuerdo con esta autora, es provocado en gran parte por "la desintegración de la agricultura familiar, así como el crecimiento del mercado moderno y la desaparición de la idea del Estado de bienestar" (2002: 10).

También es importante mencionar que, en términos de la organización social, se visualiza una flexibilización en las restricciones de las normas de filiación: se abren las posibilidades para la identificación del cónyuge y ya no se traduce en una sanción social de peso elegir uno que no pertenezca al grupo.

Aunque se sigue prefiriendo el matrimonio con personas de la misma comunidad, no puede dejar de señalarse que todos estos cambios repercuten en la continuidad de la reproducción de los elementos identitarios, que otorgan el sentido de pertenencia al grupo.

Por su parte, los programas enfocados al desarrollo agrícola y encaminados a "homologar" los grupos indígenas con el resto de la población han fracasado, ya que han sido dirigidos bajo una visión paternalista que ha mermado la capacidad de autodeterminación de la comunidad, pues en este proyecto de integración se verifica una relación en la cual la comunidad no participa en un modo equitativo, por lo cual sería importante la revisión de los términos en los que se participa como comunidad cultural dentro del sistema capitalista. Adicionalmente, no se ha logrado evitar la discriminación a los miembros de la comunidad por su origen étnico, ni las connotaciones negativas que acarrea la formulación del término "indígena”. Muestra de ello es el Padrón de Comunidades Indígenas que se realizó a través de la Identificación y registro legal de las comunidades indígenas en el Estado de Guanajuato, donde se señala que:

La población indígena del campo guanajuatense cultiva de manera marginal y sin el suficiente soporte técnico, administrativo y financiero para producir cultivos de importancia comercial [...] en estas zonas existen otros recursos naturales y culturales que no han sido suficientemente explotados por falta de capacitación, infraestructura técnica, organización y respaldo financiero (CDI, 2011).

Esto nos indica que, a pesar de las experiencias del fracaso de las políticas inducidas, el Estado mantiene una misma concepción sobre las culturas indígenas como incapaces de explotar sus recursos de forma autónoma. El Padrón de Comunidades Indígenas, en Guanajuato se observa como una política de identificación, ya que señala que "el reconocimiento de las culturas por parte del Estado lleva consigo políticas que pueden terminar por encerrar a un individuo en un comportamiento y pensamiento obligatorio y esperado de la etnia a la que pertenecen" (Gutmann, 1994;86) Si bien es cierto que en la localidad ha habido un desarrollo a nivel de la infraestructura material, también ha habido un encarecimiento de las expectativas de vida, producto del desvanecimiento social en cuanto a la reproducción de la forma de vida de los miembros de la comunidad, siendo el grupo doméstico un reducto del espacio social para la reproducción de la identidad, y de los referentes que le dan sentido a las experiencias de los miembros de la localidad. Lo que está en juego "no es la cultura en sí como centro de conflicto con la alteridad, si no la posibilidad de producirla" (Martínez, 2008: 160), libre y positivamente, bajo sus propios cánones de sentido. 


\section{Anexos}

\section{Anexo 1. Mapa de Misión de Chichimecas}

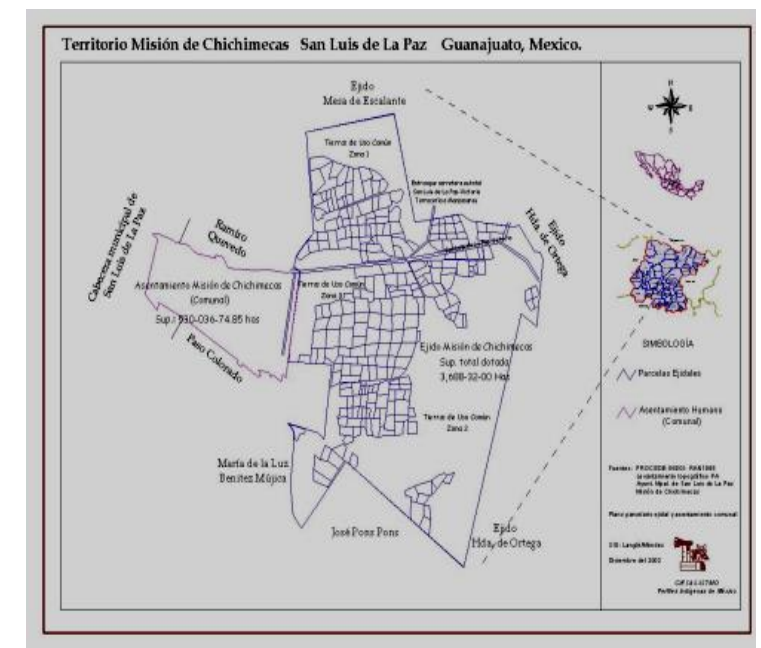

FUENTE:

http://pacificosur.ciesas.ude.mx/perfilindigena/chichimecas/extras Lmapa02.html.

Anexo 2. Distribución de las familias en el solar ${ }^{10}$

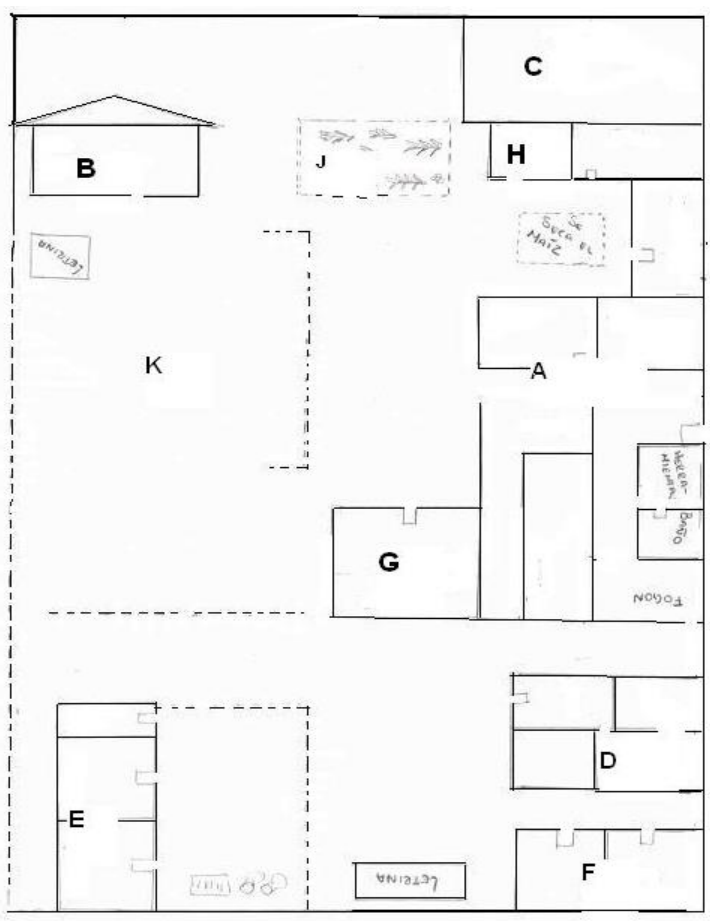

${ }^{10}$ A. Casa de los padres. B. Casa del hijo 1 (mayor) con su esposa. C. Hija 2 mayor con esposo e hijos. D. Hijo 2 con esposa e hijos. E. Hija 3 con esposo e hijo. F. Hija 4 con esposo e hijos. G. Hijo 5 menor con su esposa. H. Almacén de maíz y frijol. J. Huerta familiar. K. Patio compartido. 


\section{Bibliografía}

ALEGRE, Francisco Xavier (1956). Historia de la Compañía de Jesús. Vol. I, Roma: Institutum Historicum S. J.

AGUIRRE BELTRÁN, Gonzalo (1992). Obra antropológica VI. El proceso de aculturación. Problemas científicos y filosóficos. México: Fondo de Cultura Económica.

BURKE, Peter (2000). Historia y teoría social. México: Instituto Mora.

CASO, Alfonso (1958). Indigenismo. México: Instituto Nacional Indigenista.

Centro de Investigaciones y Estudios Superiores en Antropología Social (2001). Ubicación en el territorio nacional. Chichimeca-jonaz. Disponible en: http://pacificosur.ciesas.edu.mx/perfilindigena/chichimecas/imags/mapao 2CIESASitsmo.lhtm, consultado el 4 de septiembre de 2010.

Consejo Nacional para el Desarrollo de los Pueblos Indígenas (2011). Identificación y registro legal de las comunidades indígenas en el estado de Guanajuato. Padrón de Comunidades Indígenas. Guanajuato.

GARCÍA HERNÁNDEZ, José, "El Santuario del cerrito antiguo adoratorio chichimeca". Disponible en: www.sanluisdelapaz.com/mexico/historia/3255.html.

GIMÉNEZ, Gilberto (1994). “Comunidades primordiales y modernización”, Gilberto Giménez, Gilberto y Ricardo Pozas (coords.), Modernización e identidades sociales. México: Universidad Nacional Autónoma de México.

— (2001). "Identidades étnicas: estado de la cuestión", Leticia Reina (coord.), Los retos de la etnicidad en los Estados-Nación del siglo XXI". México: CIESAS/INI/Porrúa.

GUTMANN, Amy (1994). Multiculturalism: Examining the Politics of Recognition. Princeton: Princeton University Press.

HENRÍQUEZ MORALES, Regina et al. (1999). Diagnóstico de la Población Chichimeca Jonaz en el Estado de Guanajuato. Guanajuato: Consejo Estatal de Población (COESPO).

Instituto Nacional de Estadística y Geografía (2011). Principales Resultados por Localidad (ITER) 2010. Disponible en: www.inegi.org.mx/sistemas/consulta_resultados/iter2010.aspx, consultado el 20 de octubre de 2011.

(2011). Catálogo General de Localidades. Junio de 2010, disponible en: http://mapserver.inegi.org.mx, consultado el 10 de septiembre de 2011.

Instituto Nacional Indigenista (1970). Todos Somos Mexicanos: Misión de Chichimecas. Reedición de 2008, México: CDI.

JIMÉNEZ Moreno, Wigberto (1945). León Colonial, Ed. Bargas Rea, León, Gto.

KIRCHOFF, Paul (2002). Escritos selectos. Estudios mesoamericanistas. Vol. I, México: Universidad Nacional Autónoma de México.

MARTÍNEZ ESPINOZA, Francisco (2008). Diagnostico de Salud UMAPS Misión de Chichimecas. Guanajuato: Secretaría de Salud del Estado de Guanajuato.

MARTÍNEZ NEIRA, Christian (2008). “¿Qué son los movimientos étnicos? Las categorías de igualación y diferenciación”, Daniel Gutiérrez Martínez y Helene Balslev Clausen (coords.), Revisitar la etnicidad: miradas cruzadas en torno a la diversidad. México: El Colegio Mexiquense/El Colegio de Sonora/Siglo XXI. 
OOMMEN, T. K. (1997). Citizenchip, Nationality and Ethnicity. Cambridge: Polity Press/Blackwell Publishers.

POWELL, Phillip W. (1996). La guerra chichimeca (1550-160o). México: Fondo de Cultura Económica.

RABELL ROMERO, Cecilia Andrea (1986). Los diezmos de San Luis de la Paz: economía en una región del bajío en el siglo XVIII. México: Universidad Nacional Autónoma de México.

RAMÍREZ, Esteban (1952). Estudio histórico de San Luis de la Paz, 1552-1952, Archivo Histórico del municipio de San Luis de la Paz, Guanajuato.

ROSALDO, Renato (1991). Cruce de fronteras, en Cultura y Verdad, Grijalbo, México.

ROWLAND, Robert (1993), "Población, familia y sociedad", en Pilar Gonzalbo (Comp.), "Historia de la familia", Instituto Mora / UAM, México.

SANTA MARIA, Fray Guillermo de (2003). Guerra de los chichimecas (México, 1575-Zirosto, 1580). 2a ed., México: El Colegio de Michoacán/Universidad de Guadalajara/El Colegio de San Luis.

Secretaría de Educación Pública (1987). Diagnóstico Sociocultural del Estado de Guanajuato. Guanajuato.

SOUSTELLE, Jacques (1993). La familia otomí-pame del México central. México: Fondo de Cultura Económica.

TEJERA GAONA, Héctor (1993), "La comunidad indígena y campesina de México", en Antropología breve de México, Academia de investigación científica UNAM.

UZETA ITURBIDE, Jorge (2004). "Ejidatarios y chichimecas: identidad india a través de la formación de un ejido guanajuatense", Patricia Moctezuma Yano et al., (coords.), Guanajuato: aportes recientes para su estudio. México: El Colegio de San Luis/Universidad de Guanajuato.

VOUGHAN, Mary Kay (2002). "Introducción”, María da Gloria Marroni y María Eugenia D' Auberrete Buznego (coords.), Con voz propia. Mujeres rurales en los noventa. México: Benemérita Universidad Autónoma de Puebla. 